\title{
Looking back, looking ahead
}

\author{
Joseph Flynn ${ }^{1,2} \cdot$ Lesley Rees $^{3}$
}

Published online: 3 February 2022

○ The Author(s), under exclusive licence to International Pediatric Nephrology Association 2022

As 2021 comes to a close, Pediatric Nephrology has much to celebrate, including a renewed publishing contract between IPNA and Springer, and a substantial increase in impact factor to 3.714 for $2020 / 21$ from 2.676 for 2019 . The higher impact factor reflects a notable increase in the number of citations of papers published in the journal, which was accompanied by an increase in the number of papers downloaded from the journal website. We also have been able to maintain a rapid time to first decision of just 15 days, and have reduced our backlog of online-only papers by expanding the number of articles published in each issue of the journal.

COVID-19 continued to have substantial impact on journal operations in 2021, primarily making it harder for us to find reviewers, many of whom had to decline review invitations because of heavier than usual clinical workloads imposed by the pandemic. The marked increase in submissions that was seen in 2020 ( 1000 submissions, compared to $\sim 700$ /year previously) declined somewhat - although the final tally isn't yet in, it looks like there will be close to 900 submissions by the end of the year, still an increase, and leading to more work for our editorial and production staffs. Fortunately, with the hiring of a full-time managing editor for the Seattle editorial office, the backlog of work that had accumulated by the end of 2020 has been largely cleared, and we hope that 2022 will be more manageable than 2020 and 2021.

Another accomplishment of 2021 was expansion of the journal's editorial board to include more members from Asia and the United States. This should help us to maintain our position as the natural publishing "home" for pediatric nephrologists globally, and to help us better serve our international readership. We thank these new editorial board members in advance for their contributions to the ongoing work of the journal. And we thank those who have left the editorial board in 2021, and know that we can still count on them for support in the future. We also thank three Associate Editors who are stepping down as of the end of 2021: Carl Bates, Stephen Marks and Dieter Haffner. Their replacements will be Tomas Seeman, Kevin Lemley and Kazumoto Iijima, who will join Rosanna Coppo, Elena Levtchenko, Detlef Bockenhauer and Kate Wesseling-Perry. The Associate Editors have the important role of inviting Reviews and Educational Reviews, which tend to be frequently cited, and therefore have an outsize impact on the impact factor. We are excited by this new team and its potential for further expanding the journal's reach.

Joseph Flynn

joseph.flynn@seattlechildrens.org

1 Division of Nephrology, Seattle Children's Hospital, 4800 Sand Point Way NE, Seattle, WA 98105, USA

2 Department of Pediatrics, University of Washington School of Medicine, Seattle, WA, USA

3 Pediatric Nephrology, UCL Great Ormond Street Institute of Child Health, UCL, London, UK 
2021 was also the first full year of Joseph Flynn's tenure as Co-Editor-in-Chief, and of Bob Thompson's position as managing editor in Seattle. It has been a learning year for both Joseph and Bob, who appreciate the tutelage and patience of Lesley Rees and Joseph Laycock over the past 12 months. In 2022, IPNA will initiate a search for the next Co-Editor-in-Chief, as Lesley Rees's term will come to a close at the end of the year.

Finally, we thank our readership for their support of the journal. We could not accomplish any of the things mentioned here without your submissions, your reviews of manuscripts, and your suggestions for improvement. Even though the COVID-19 pandemic has prevented us from interacting in person, we hope that you feel connected to the journal, and to us, and that this connection will remain strong in the years ahead.
Seasons Greetings,

Joseph and Lesley.

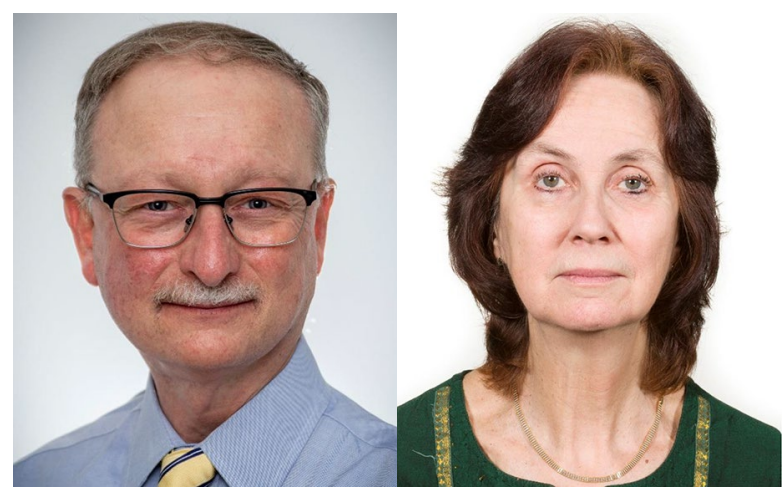

Publisher's note Springer Nature remains neutral with regard to jurisdictional claims in published maps and institutional affiliations. 